\title{
EFFECTS OF COMBINATIONS OF PATTERNMAKING METHODS AND DRESS FORMS ON GARMENT APPEARANCE
}

\author{
Chinami Fujii', Masayuki Takatera², KyoungOk Kim² \\ ${ }^{1}$ Shinshu University, Graduate School of Science and Technology, Ueda, Nagano, 3-15-1 Tokida, 386-8567, Japan. \\ ${ }^{2}$ Division of Kansei and Fashion Engineering, Institute for Fiber Engineering (IFES), Interdisciplinary Cluster for Cutting Edge Faculty of Textile Science and \\ Technology, Shinshu University, 3-15-1 Tokida, Ueda, Nagano 386-8567, Japan. \\ Corresponding author e-mail: kimko@shinshu-u.ac.jp
}

\begin{abstract}
:
We investigated the effects of the combinations of patternmaking methods and dress forms on the appearance of a garment. Six upper garments were made using three patternmaking methods used in France, Italy, and Japan, and two dress forms made in Japan and France. The patterns and the appearances of the garments were compared using geometrical measurements. Sensory evaluations of the differences in garment appearance and fit on each dress form were also carried out. In the patterns, the positions of bust and waist darts were different. The waist dart length, bust dart length, and positions of the bust top were different depending on the patternmaking method, even when the same dress form was used. This was a result of differences in the measurements used and the calculation methods employed for other dimensions. This was because the ideal body shape was different for each patternmaking method. Even for garments produced for the same dress form, the appearances of the shoulder, bust, and waist from the front, side, and back views were different depending on the patternmaking method. As a result of the sensory evaluation, it was also found that the bust and waist shapes of the garments were different depending on the combination of patternmaking method and dress form. Therefore, to obtain a garment with better appearance, it is necessary to understand the effects of the combinations of patternmaking methods and body shapes.
\end{abstract}

\section{Keywords:}

basic pattern, appearance, sensory evaluation

\section{Introduction}

In clothing production, a patternmaker makes a pattern according to illustrations created by a designer. Even when the same design illustrations are used, the silhouette and shape of the final clothing could differ depending on the skills, experience, and proficiency of the patternmaker, which, in turn, can affect the appearance of the clothing [1]. A patternmaker manufactures a pattern using either a draping or flat patternmaking method based on specific measurements. A basic pattern can be modified to create patterns for a specific design. Many flat patternmaking methods for basic patterns have been developed by educational institutions and companies, and sometimes by individual patternmakers. A variety of patternmaking methods have been published in various countries for educational purposes [2-8].

Basic patterns can have a significant effect on the final clothing product in terms of appearance and comfort, even after patternmakers modify them according to specific design and size requirements. There have been some studies on the classification of body types to create fitted garments [911]. There have also been some studies on the construction of a basic pattern that enables the production of comfortable, good-fitting clothing taking into account the wearer's body type [12-14]. The relationships between darts, ease allowance, and goodness of fit have been investigated with a view to producing comfortable garments $[15,16]$. The aesthetics of clothing in relation to body type has long been an important topic of discussion in clothing manufacture [17]. However, it is still unclear which patternmaking method is most suited to producing clothing of good appearance for various body shapes. The combination of the patternmaking method and the body shape will affect the appearance of a garment. Furthermore, standard body shapes differ depending on race or ethnicity. It is therefore necessary to understand the suitability of patternmaking for clothing designs aimed at the global market.

To clarify the effects of the combinations of patternmaking methods and body shapes on the appearance of clothing, we investigated the difference between patternmaking methods in various countries. We compared three methods for making basic patterns in France, Italy, and Japan by creating basic upper garment patterns for dress forms made in France and Japan. The relationship between the appearance of the garment and the combination of patternmaking method and dress form was also investigated. Sensory evaluations of the garments' appearance and goodness of fit were also performed.

\section{Experimental research}

To investigate the effects of patternmaking methods on the appearance of basic upper garment patterns, we carried out the following experiments. 
1) Comparison of basic patterns made by three patternmaking methods

2) Comparison of the garments' appearance on a dress form

3) Sensory evaluation of the garments' appearance and goodness of fit

\subsection{Comparison of basic patterns}

Three patternmaking methods [2-4], proposed by representative dressmaking schools in Italy, Japan, and France, were used to make a basic bodice pattern without sleeve. From the Secoli Institute in Italy [2], an upper part of a basic pattern for a one-piece garment with a tight waistline was selected. From Educational Foundation Bunka Gakuen [3] as well as ESMOD International [4] in France, we selected a basic pattern for a bodice. We also selected two dress forms: (a) a Japanese size 9AR (KIIYA Co., New Kypris model 9AR, Tokyo, Japan) and (b) a French one (Siegel \& Stockman, BUSTE model B497 38, Paris, France), whose size corresponded to size 9AR in Japanese Industrial Standards. Figure 1 shows photographs of the dress forms and Table 1 shows the measurements of each dress form. Although both dress forms are of similar size, the silhouette and the bust point (BP) placements were different. The ratios of the length from the side neck point (SNP) and the $\mathrm{BP}$ to the length between the BP and the waist (W) were also different, as shown in Table 2. Figure 2 shows a comparison of dress form shapes from the side view. Table 3 shows the measurements used for each patternmaking method.

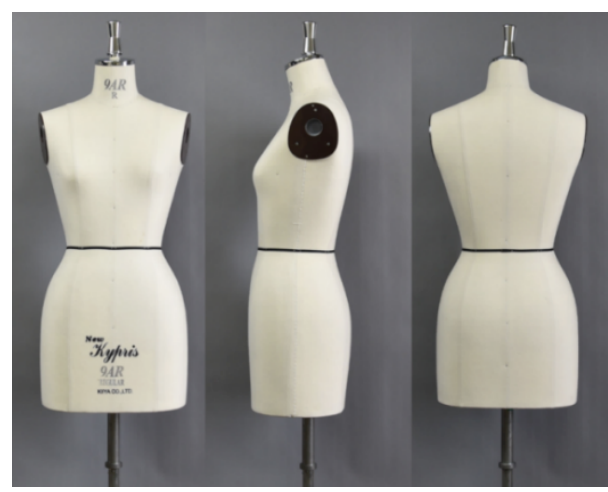

(a) Kiiya dress form

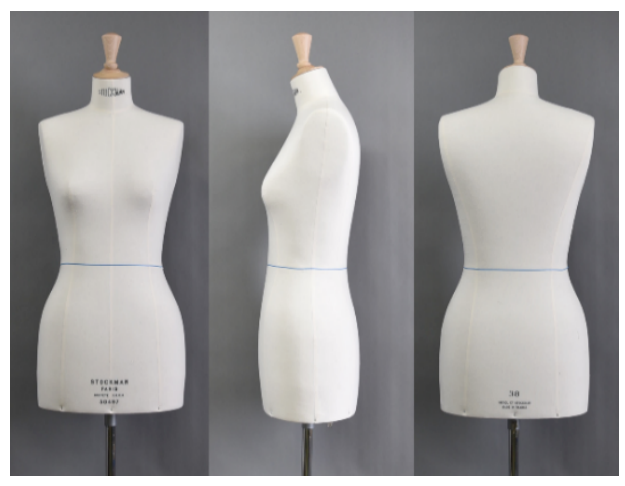

(b) Stockman dress form

Figure 1. Front, side, and back views of dress forms
Table 1. Measurements of dress forms (in $\mathrm{cm}$ )

\begin{tabular}{|c|c|c|c|}
\hline \multirow{2}{*}{ Symbol } & \multirow{2}{*}{ Measurement } & \multicolumn{2}{|c|}{ Dress form } \\
\hline & & Kiiya & Stockman \\
\hline S & Height & 158.0 & 158.0 \\
\hline $\mathrm{B}$ & Bust circumference & 85.8 & 86.2 \\
\hline $\mathrm{BL}$ & $\begin{array}{c}\text { Bust length (front } \\
\text { neck point-bust point) }\end{array}$ & 18.0 & 21.0 \\
\hline $\mathrm{T}$ & Thorax circumference & 87.0 & 85.5 \\
\hline W & Waist circumference & 63. & 67.5 \\
\hline $\mathrm{P}$ & Back waist length & 38.4 & 41.0 \\
\hline $\mathrm{C}$ & $\begin{array}{l}\text { Front waist length } \\
\text { (from front neck point } \\
\text { to waist line) }\end{array}$ & 33.5 & 36.5 \\
\hline FRS & $\begin{array}{l}\text { Front waist length } \\
\text { (from the seventh } \\
\text { cervical vertebra } \\
\text { to waistline passes } \\
\text { through the bust } \\
\text { point.) }\end{array}$ & 48.8 & 49 \\
\hline BNC & $\begin{array}{c}\text { Back neck } \\
\text { circumference }\end{array}$ & 7.8 & 7.6 \\
\hline SI & Shoulder length & 12.9 & 12.8 \\
\hline Sa & $\begin{array}{c}\text { Shoulder angle } \\
\text { (degree) }\end{array}$ & 20 & 15 \\
\hline BBP & Between bust points & 16.9 & 18.3 \\
\hline $\mathrm{Cb}$ & Cross-back* & 36.2 & 34.5 \\
\hline Cf & Cross-front ${ }^{*}$ & 32.0 & 32.0 \\
\hline $\mathrm{Hi}$ & Hip circumference & 91.0 & 91.0 \\
\hline
\end{tabular}

${ }^{*}$ cross-back $(\mathrm{Cb})$ : The line between center of back bust line and center of back neck line, parallel to the waistline.

${ }^{*}$ cross-front (Cf): The line between center of front bust line and center of front waist line, parallel to the waistline.

We made six basic upper garment patterns, using the three patternmaking methods for each of the two dress forms. Ease allowances in each pattern were set according to the each method because it is not parameterized. The patterns were made using apparel CAD and the six patterns produced following the three patternmaking methods for each dress form were compared. Figure 3 shows the measuring points for the darts. Because shapes of waist and bust darts in the patternmaking methods were different, we compared length and width of the darts. Waist darts are numbered from the front center line to the back center line (d1-d7). We called the darts directed to BP from the shoulder and armhole the bust dart. The placement of the BP was determined by an equation in each patternmaking method. The length of the dart base is the width (w) and the perpendicular length from the dart base to the top is the height $(h)$. To evaluate the waist constriction, we calculated the percentage of the sum of all waist darts widths (SAD) to the sum of waist and all waist darts (WD).

We also measured the shoulder angle of the dress forms and the made garments using an angle meter. In the front and back patterns, the angles between the shoulder lines and the transverse line were deemed the shoulder angle of the pattern. 
Table 2. Dress form balance from the side

\begin{tabular}{|c|c|}
\hline Dress form Part & $(\mathrm{SNP}-\mathrm{BP}) /(\mathrm{BP}-\mathrm{W})$ \\
\hline Kiiya & 1.15 \\
\hline Stockman & 1.23 \\
\hline
\end{tabular}

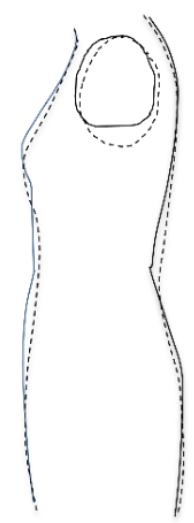

Kiiya: solid line, Stockman: dotted line

Figure 2. Comparison of dress form shapes from the side

\subsection{Effect of pattern on appearance}

To investigate the effects of combinations of patternmaking methods and dress forms on appearance, we made six garments (three patternmaking methods $\times$ two dress forms) using a cotton fabric. We placed each garment on each dress form and compared the appearance from the front, side, and back.

\subsection{Sensory evaluation of appearance}

We investigated impressions regarding the appearance of the garments as they were placed on the dress forms. We took pictures of the garments on the dress forms from the front, side, and back. We used the questionnaire items shown in Table 4, and the responses were measured on a scale of 1 to 5. Subjects compared pictures of two garments and answered the questions on the designated parts viewed from the front, side, and back, respectively, according to Scheffe's paired comparison (Nakaya variation) without considering sample order [18]. The results were analyzed using analysis of variance (ANOVA). Figure 4 shows the parts of the garments that were evaluated. Table 5 shows the sample combinations used in the evaluation. Group 1 used the measurements of the Kiiya dress form and group 2 used the measurements of the Stockman dress form. The subjects were 20 female Japanese university students aged in their 20 s.

\section{Results and discussion}

\subsection{Pattern comparison}

Figures 5 and 6 show the patterns that were created. As shown in Table 3, different measurements were used in making the patterns. In the Secoli method, height $(\mathrm{S})$, bust $(\mathrm{B})$, thorax $(T)$, and length between both BPs (BBP) were used. $T$ is the
Table 3. Measurements used for patternmaking

\begin{tabular}{|c|c|c|c|}
\hline \multirow{2}{*}{ Symbol } & \multicolumn{3}{|c|}{ Methods } \\
\hline & (a) Secoli & (b) Bunka & (c) ESMOD \\
\hline S & 0 & & \\
\hline B & 0 & 0 & 0 \\
\hline BL & & & 0 \\
\hline T & 0 & & \\
\hline W & & & 0 \\
\hline SI & & & 0 \\
\hline P & & & 0 \\
\hline C & & & \\
\hline FRS & & & \\
\hline BNC & & & \\
\hline BBP & & & \\
\hline Cb & & & \\
\hline Cf & & & \\
\hline Hi & & & \\
\hline
\end{tabular}

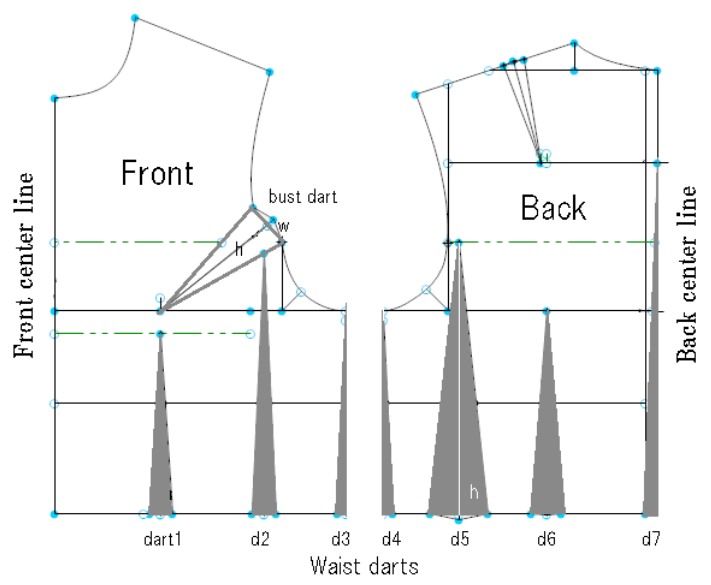

Figure 3. Measuring points of darts

length measured just below the armpit. In the Bunka method, $B, W$, and back waist length $(P)$ were used. To calculate other measurements, equations of $B$ were used. In the ESMOD method, nine measurements were used, as shown in Table 3. Although the Bunka and Secoli methods used for waist measurements, the waist measurement in the ESMOD method was calculated using the hip and bust measurements.

Different methods were used to set the BP position, depending on each making method. Each method for $X$ and $Y$ axis of $B P$ position was compared as setting the origin of the $\mathrm{X}$-axis and the $\mathrm{Y}$-axis as the center line and waistline, respectively, as shown in Figure 7.

$X S$ and $Y S$, which are the $X$ and $Y$ of BP positions by the Secoli method, are obtained using equation (1) and (2). 
Table 4. Questionnaire items

\begin{tabular}{|c|c|c|}
\hline Number & Part & 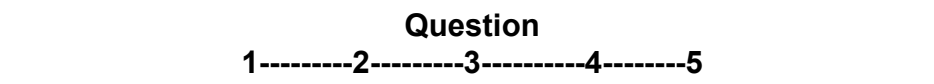 \\
\hline Question-1 & All & $\begin{array}{c}\text { Similarity of overall silhouette } \\
\text { (Not similar) - } \\
1=\text { not at all, } 2=\text { somewhat, } 3=\text { neutral, } 4=\text { quite well, } 5=\text { very well }\end{array}$ \\
\hline Question-2 & $A, B, C$ & $\begin{array}{c}\text { Poor fit or good fit } \\
1 \text { (Good fit) }- \text { very good, } 2=\text { good, } 3=\text { average, } 4=\text { bad, } 5=\text { very bad. }\end{array}$ \\
\hline
\end{tabular}

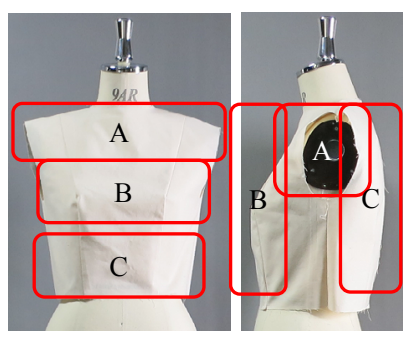

(1) Front

(2) Side

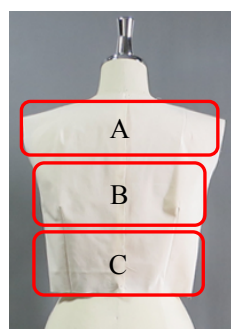

(3) Back

Figure 4. Evaluated parts

evaluation

Table 5. Combinations of patternmaking methods and dress forms for sensory evaluation

\begin{tabular}{|c|c|c|c|}
\hline \multicolumn{2}{|c|}{ Symbol } & Patternmaking method & Dress form \\
\hline \multirow{3}{*}{ Group 1 } & $\mathrm{a} 1$ & Secoli & \multirow{2}{*}{ Kiiya } \\
\cline { 2 - 3 } & $\mathrm{b} 1$ & Bunka & \\
\cline { 2 - 3 } & $\mathrm{c} 1$ & ESMOD & \multirow{2}{*}{ Stockman } \\
\cline { 2 - 3 } Group 2 & $\mathrm{a} 2$ & Secoli & \\
\cline { 2 - 3 } & $\mathrm{b} 2$ & Bunka & ESMOD \\
\hline
\end{tabular}

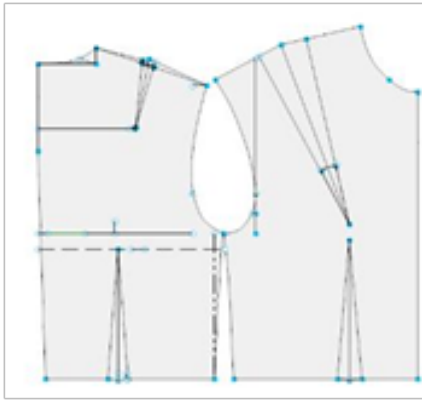

(a) Secoli

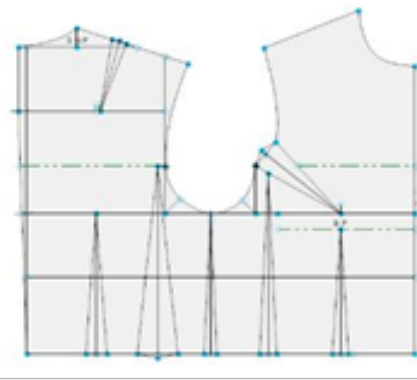

(b) Bunka

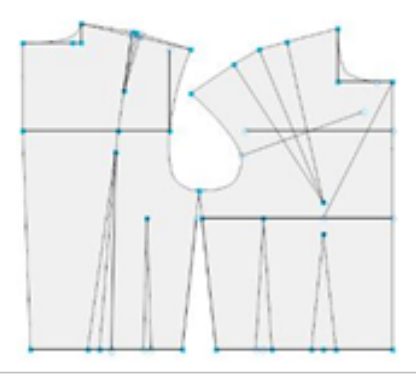

(c) ESMOD

Figure 5. Patterns using Kiiya measurements

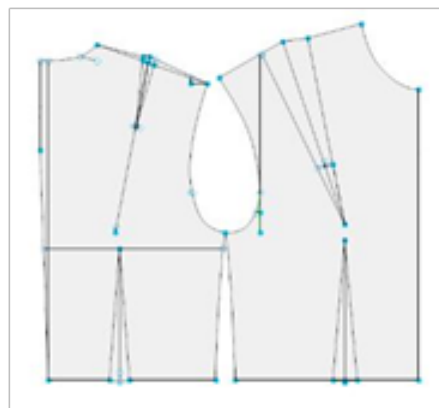

(a) Secoli

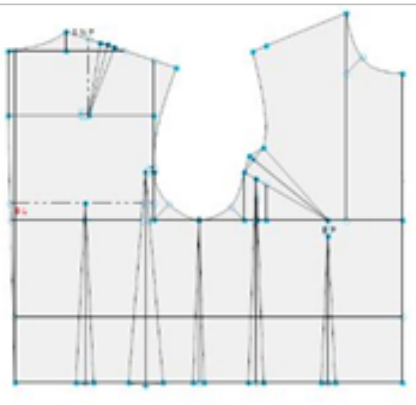

(b) Bunka

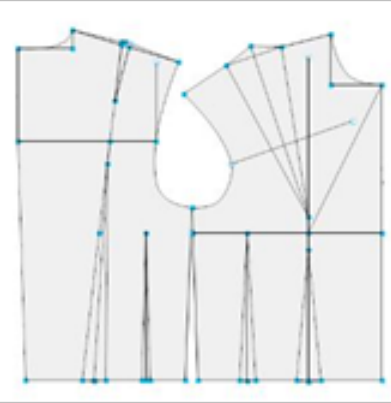

(c) ESMOD

Figure 6. Patterns using Stockman measurements 


$$
\begin{gathered}
\mathrm{X}_{\mathrm{S}}=\frac{\mathrm{BBP}}{2} \\
\mathrm{Y}_{\mathrm{S}}=\mathrm{FRS}-\sqrt{\left(\frac{\mathrm{S}}{8} \times 1.7-1-\mathrm{BNC}\right)^{2}-\left(\frac{\mathrm{BBP}}{2}-\frac{\mathrm{T}}{20}+2.8\right)^{2}}
\end{gathered}
$$

In the Bunka method, the position of $X B$ and $Y B$ are obtained using equations ( 3 ) and (4).

$$
\begin{aligned}
& X_{B}=(B / 8+6.2) / 2+0.7 \\
& Y_{B}=P-(B / 12+13.7)
\end{aligned}
$$

In the Esmod method, the position of XE and YE are obtained using equations (5) and (6).

$$
\begin{aligned}
& X_{E}=\frac{B B P}{2} \\
& Y_{E}=C-\sqrt{\left(B L^{2}-(B B P / 2)^{2}\right)}+2
\end{aligned}
$$

Figure 8 shows the BP positions for the various combinations of dress forms and their patterns. The BP placements in the patterns made for the same dress form differed depending on the patternmaking method used. For the Kiiya dress form, both the $\mathrm{X}$ and $\mathrm{Y}$ coordinates of the BP for the Bunka pattern differed from those of the dress form. The $X$ coordinates of patterns made by Secoli and ESMOD were close to that of the dress form, although the $Y$ coordinates were different. The same results were found with the Stockman dress form. The patterns made by Bunka for the Kiiya and Stockman dress forms both showed a similar BP position.

The bust darts were drawn from the shoulder line to the BP in the Secoli and ESMOD patterns, while those in the Bunka pattern were drawn from the armhole to the BP. Table 6 shows the bust dart width, height, and area in each pattern. In the Secoli and Bunka patterns, there were no differences in the width and height of the darts between the dress forms. However, in the ESMOD patterns, the dart heights differed depending on the dress form used.

Table 7 shows the sum of all waist darts for each pattern. The waist of the pattern made using the Secoli method was larger than the others because of the shorter height of the waist darts. Therefore, it was expected that the waist silhouette of the Secoli pattern would appear to have a looser shape than the others.

Table 8 shows the shoulder angles of the patterns. The shoulder angles of the patterns made by ESMOD were different depending on the dress form, although the patterns made by Secoli and Bunka showed few differences between the dress forms. The shoulder angles of the Bunka patterns were constants determined by the patternmaking method.

The waist ease allowances of each pattern are shown in Table 9. The waist ease allowance of the Secoli patterns was considerably larger than that of the Bunka patterns, while that of the ESMOD patterns was almost zero.

Figure 9 shows superimposed patterns for the Kiiya and Stockman dress forms for each patternmaking method. The patterns were superimposed based on the armpit point.

In the Secoli method, $T$ was used to calculate other measurements. There was a difference of $1.5 \mathrm{~cm}$ between the T of the Kiiya dress form and that of the Stockman dress form. However, the effect was smaller because only fractions of $T$,

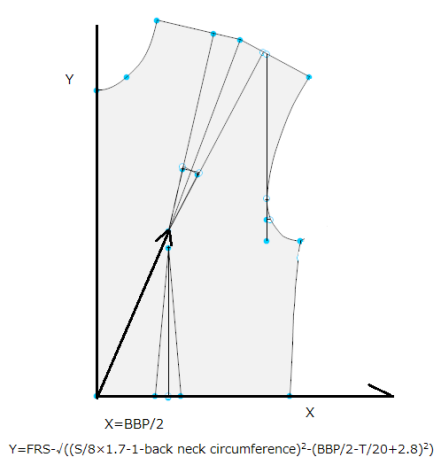

(a) Secoli

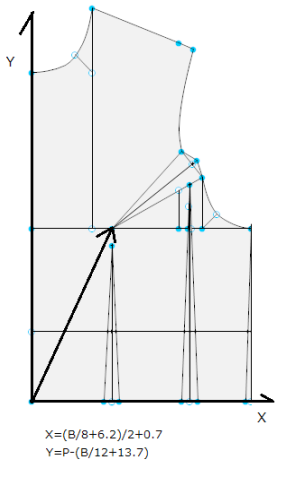

(b) Bunka

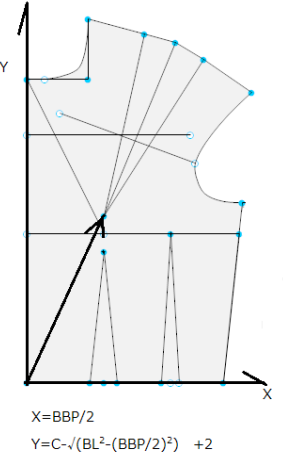

(c) ESMOD

Figure 7. Method of defining BP position

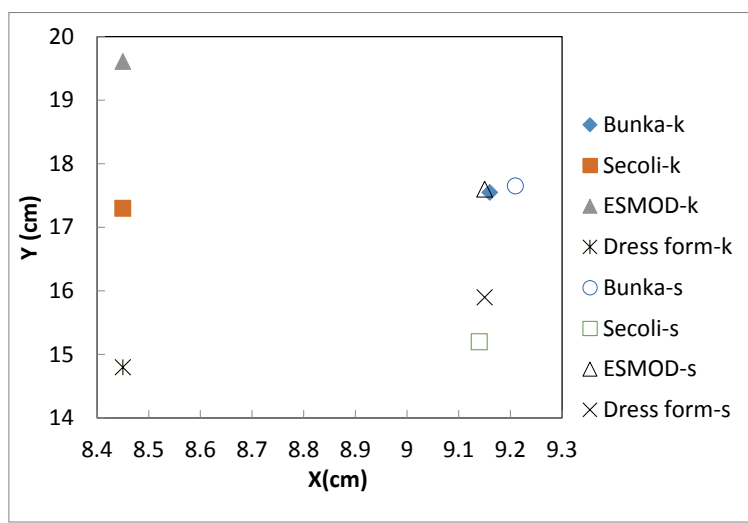

Figure 8. BP position in patterns and dress forms (k: Kiiya, s: Stockman) 
Table 6. Dimensions of bust darts

\begin{tabular}{|c|c|c|c|c|c|c|}
\hline Method & \multicolumn{2}{|c|}{ (a) Secoli } & \multicolumn{2}{c|}{ (b) Bunka } & \multicolumn{2}{c|}{ (c) ESMOD } \\
\hline Dress form & Kiiya & Stockman & Kiiya & Stockman & Kiiya & Stockman \\
\hline Width $(\mathrm{cm})$ & 6.18 & 6.11 & 3.95 & 3.84 & 12.15 & 7.18 \\
\hline Height $(\mathrm{cm})$ & 24.02 & 23.88 & 12.52 & 20.70 & 22.32 \\
\hline Area $\left(\mathrm{cm}^{2}\right)$ & 74.22 & 72.95 & 24.73 & 24.08 & 74.00 & 80.13 \\
\hline
\end{tabular}

Table 7. Size of waist darts

\begin{tabular}{|c|c|c|c|c|c|c|c|c|}
\hline \multirow{2}{*}{\multicolumn{3}{|c|}{$\begin{array}{c}\text { Method } \\
\text { Dress form }\end{array}$}} & \multicolumn{2}{|c|}{ (a) Secoli } & \multicolumn{2}{|c|}{ (b) Bunka } & \multicolumn{2}{|c|}{ (c) ESMOD } \\
\hline & & & \multirow{2}{*}{$\begin{array}{c}\text { Kiiya } \\
3.00\end{array}$} & \multirow{2}{*}{$\begin{array}{c}\text { Stockman } \\
3.00\end{array}$} & \multirow{2}{*}{$\begin{array}{c}\text { Kiiya } \\
2.01\end{array}$} & \multirow{2}{*}{$\begin{array}{c}\text { Stockman } \\
1.73\end{array}$} & \multirow{2}{*}{$\begin{array}{c}\text { Kiiya } \\
3.00\end{array}$} & \multirow{2}{*}{$\begin{array}{c}\text { Stockman } \\
3.00\end{array}$} \\
\hline \multirow{8}{*}{ 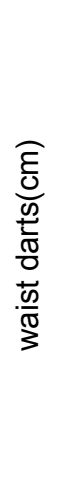 } & \multirow{3}{*}{ Front } & dart 1 & & & & & & \\
\hline & & dart 2 & 1.20 & 1.20 & 2.16 & 1.85 & 2.00 & 2.00 \\
\hline & & dart 3 & & & 0.79 & 0.68 & 2.05 & 0.80 \\
\hline & \multirow{4}{*}{ Back } & dart 4 & 2.50 & 2.50 & 5.03 & 4.32 & 1.00 & 1.00 \\
\hline & & dart 5 & 0.91 & 1.00 & 2.59 & 2.22 & 3.00 & 3.00 \\
\hline & & dart 6 & 1.20 & 1.20 & 1.00 & 0.86 & 1.00 & 1.00 \\
\hline & & dart 7 & & & 0.79 & 0.68 & 2.05 & 0.80 \\
\hline & \multicolumn{2}{|c|}{ Sum of all darts (SAD) } & 8.81 & 8.90 & 14.37 & 12.34 & 14.10 & 11.60 \\
\hline \multicolumn{3}{|c|}{ Waist + SAD (WD) } & 84.99 & 85.25 & 83.43 & 85.82 & 77.08 & 79.1 \\
\hline \multicolumn{3}{|c|}{ SAD/WD (\%) } & 10.37 & 10.44 & 17.22 & 14.38 & 18.29 & 14.66 \\
\hline
\end{tabular}

Table 8. Shoulder angle of pattern (in degrees)

\begin{tabular}{|c|c|c|c|}
\hline \multirow{2}{*}{ Method } & \multirow{2}{*}{ Pattern } \\
\cline { 2 - 4 } & Dress form & Front & 14.1 \\
\hline \multirow{2}{*}{ Secoli } & Kiiya & 13.5 & 14.1 \\
\hline \multirow{2}{*}{ Bunka } & Stockman & 14.5 & 18.0 \\
\cline { 2 - 4 } & Kiiya & 22.0 & 18.0 \\
\cline { 2 - 4 } & Stockman & 22.0 & 9.1 \\
\hline \multirow{2}{*}{ ESMOD } & Kiiya & 15.1 & 12.7 \\
\hline
\end{tabular}

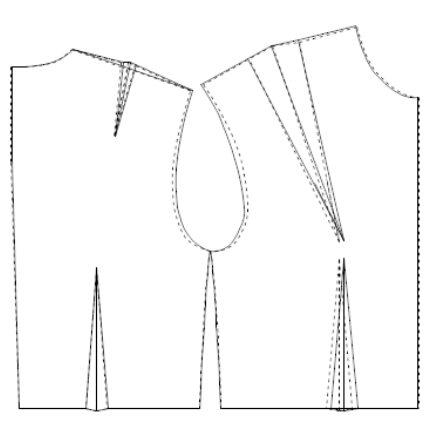

(a) Secoli

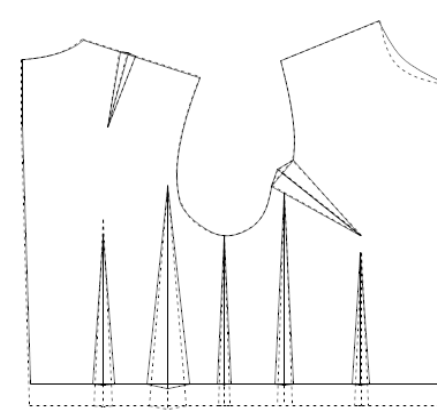

(b) Bunka

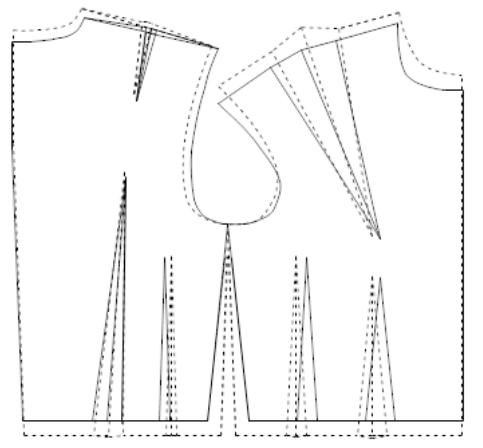

(c) ESMOD

(Kiiya: solid line, Stockman: dotted line)

Figure 9. Comparison of patterns for different dress forms 
Table 9. Waist ease allowance $(\mathrm{cm})$

\begin{tabular}{|c|c|c|c|c|c|c|}
\hline Dress form & \multicolumn{3}{|c|}{ Kiiya } & \multicolumn{3}{|c|}{ Stockman } \\
\cline { 1 - 2 } $\begin{array}{c}\text { Making } \\
\text { method }\end{array}$ & $\begin{array}{c}\text { Dimension of } \\
\text { pattern }\end{array}$ & $\begin{array}{c}\text { Dimension of } \\
\text { body }\end{array}$ & Allowance & $\begin{array}{c}\text { Dimension of } \\
\text { pattern }\end{array}$ & $\begin{array}{c}\text { Dimension of } \\
\text { body }\end{array}$ & Allowance \\
\cline { 1 - 2 } Secoli & 76.18 & & 13.18 & 76.38 & & 8.88 \\
\hline Bunka & 69.06 & \multirow{2}{*}{63.00} & 6.06 & 73.48 & 67.50 & 5.98 \\
\cline { 1 - 1 } & & -0.02 & 67.50 & & 0.00 \\
\hline
\end{tabular}

such as $2 / 5$ and $1 / 10$, were used in equations for the back and bust widths. Therefore, there was almost no difference between the patterns for the two dress forms.

In the Bunka method, the lengths of the patterns for each dress form were different. Actual measurements were used for the length of the back, and there was a difference of $2.6 \mathrm{~cm}$ between the Kiiya and Stockman dress forms. Equation of $B$ was used to determine the measurements except waist and back length in Bunka method. Although there was a difference of $1.2 \mathrm{~cm}$ between the busts of the two dress forms, it did not affect the patterns. There were almost no difference in the measurements of the other parts.

In the ESMOD method, the shape, length, and the position of the BP differed between patterns for each dress form. The dimensions of bust darts and waist darts were also different, as shown in Tables 6 and 7. The position of the BP was determined by the $\mathrm{BL}$ and half of the width between the BPs. When the length from the BP to the waistline was long, the waist darts were less tight due to the smaller acute angle, and vice versa.

Consequently, it was found that the dimensions of darts and the BP position were different in each patternmaking method. This was due to the differences in measurements from the equations used, which assumed an ideal body shape in each patternmaking method.

\subsection{Comparison of garment appearance}

The garments created by different methods were placed on each dress form. Figures 10-12 show the three garments made using the Kiiya dress form measurements placed on the Kiiya dress form. The garment made by ESMOD using the Kiiya dress form measurements was barely able to be placed on the dress form because the bust was too tight. This was because of the large dimensions of waist darts and different BP positions. The garment was pulled higher due to the higher BP position than that on the dress form, and the shoulder did not fit the dress form.

From the front, although the BP position and waist allowance differed among the three patterns, this was not noticeable in the appearance of the garments. Table 10 shows the shoulder angles of the garments placed on each dress form. The shoulder shapes and angles differed depending on the patternmaking method used. The shoulder shape in the Bunka pattern was sloping, and that in the ESMOD pattern was square, as shown in Figure 10.
From the side, the bust shapes differed depending on the patternmaking method used. The BP of the Secoli pattern was placed below the BP of the dress form. Thus, it did not fit the bust. In the Bunka pattern, the position of the BP was close to the BP position of the dress form. However, an angulated shape was apparent as a result of the long darts. In the ESMOD pattern, the end position of the bust darts was $2 \mathrm{~cm}$ higher than the BP position in the pattern. Therefore, this gave the appearance of a bowl shape. The curves of the back and the bust differed from the side view. The silhouettes of the waists were also different. The front and back waist silhouettes of the Secoli pattern were linear, while those of the ESMOD pattern looked tight, with no allowance. From the back, there were differences in terms of shoulder shape and waist constriction.

Figures 13-15 show the three garments made using the Stockman dress form measurements placed on the Stockman dress form. From the front, the shape of the garment made using the Secoli pattern was similar to that on the Kiiya dress form. However, there were wrinkles in the armpit and around the armhole, which was not evident on the garment on the Kiiya dress form.

From the side, there were almost no differences in the shape of the garments compared with those on the Kiiya dress form. However, they appeared to be more slender than those on the Kiiya dress form. The Secoli garment did not fit the back shoulder of the dress form because the ease allowance of the armhole was not appropriate for the dress form. From the back, the garments were similar in appearance to those on the Kiiya dress form.

\subsection{Sensory evaluation of appearance}

Table 11 shows the significant differences in the paired comparison results for the front, side, and back views. As regards question 1 , there were significant differences in appearance between $\mathrm{a} 1$ and $\mathrm{c} 1$ and between $\mathrm{b} 1$ and $\mathrm{c} 1$ from the front. However, from the side, there were significant differences between all pairs except $a 1$ and b1. From the back, there were significant differences between all pairs except a1 and b1, and a2 and b2. Thus, it was found that the appearance from the side and back differed depending on the combination of patternmaking method and dress form.

For question 2, there were many significant differences between the bust and waist parts. Thus, it was found that the appearance of the bust and waist parts differed depending on the combination of patternmaking method and dress form. 
AUTEX Research Journal, Vol. 17, № 3, September 2017, DOI: 10.1515/aut-2016-0020 ๑ AUTEX

Table 10. Shoulder angle of garments and difference between dress form and garment (degrees)

\begin{tabular}{|c|c|c|c|c|c|c|c|}
\hline \multirow{2}{*}{$\begin{array}{l}\text { Drawing } \\
\text { method }\end{array}$} & \multirow[t]{2}{*}{ Measurement } & \multicolumn{2}{|c|}{ Garment on dress form } & \multicolumn{2}{|c|}{ Dress form } & \multicolumn{2}{|c|}{$\begin{array}{l}\text { Difference between dress form } \\
\text { and garment on dress form }\end{array}$} \\
\hline & & Kiiya & Stockman & Kiiya & Stockman & Kiiya & Stockman \\
\hline \multirow{2}{*}{ Secoli } & Kiiya & 18 & 19 & \multirow{6}{*}{20} & \multirow{6}{*}{15} & -2 & +4 \\
\hline & Stockman & 21 & 18 & & & +1 & +3 \\
\hline \multirow{2}{*}{ Bunka } & Kiiya & 22 & 22 & & & +2 & +7 \\
\hline & Stockman & 21 & 21 & & & +1 & +6 \\
\hline \multirow{2}{*}{ ESMOD } & Kiiya & 13 & 8 & & & -7 & -7 \\
\hline & Stockman & 19 & 18 & & & -1 & +3 \\
\hline
\end{tabular}

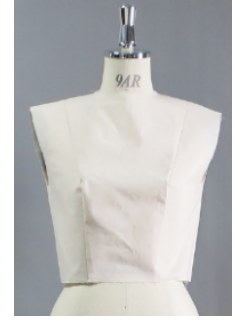

(a) Secoli

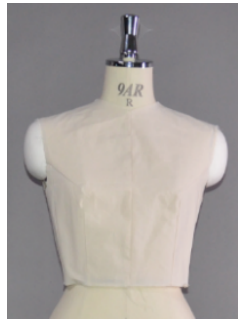

(b) Bunka

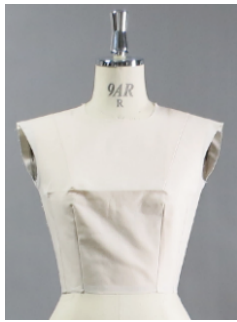

(c) ESMOD

Figure 10. Front view of garments on Kiiya dress form

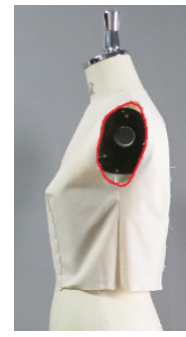

(a) Secoli

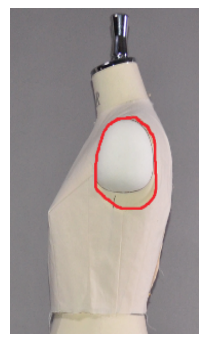

(b) Bunka

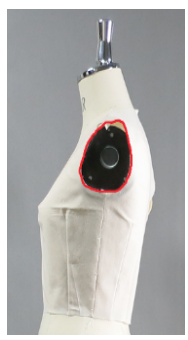

(c) ESMOD

Figure 11. Side view of garments on Kiiya dress form

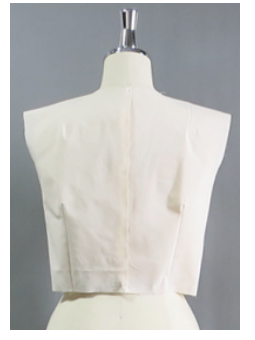

(a) Secoli

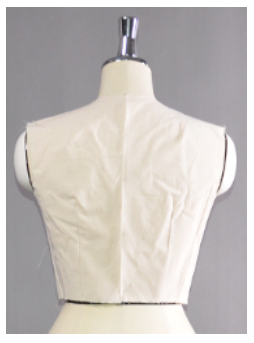

(b) Bunka

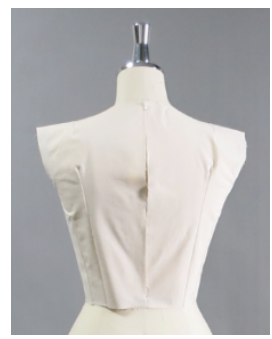

(c) ESMOD

Figure 12. Back view of garments on Kiiya dress form

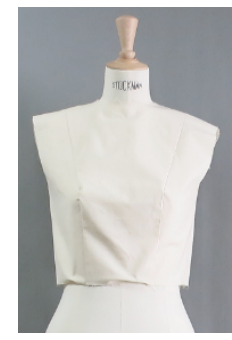

(a) Secoli

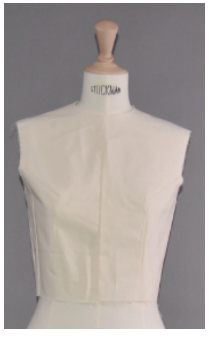

(b) Bunka

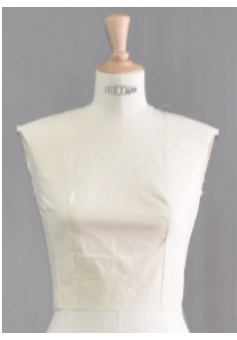

(c) ESMOD

Figure 13. Front view of garments on Stockman dress form 


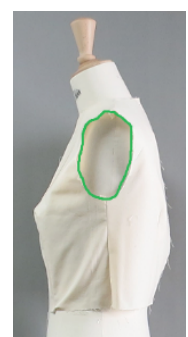

(a) Secoli

Figure 14. Side view of garments on Stockman dress form

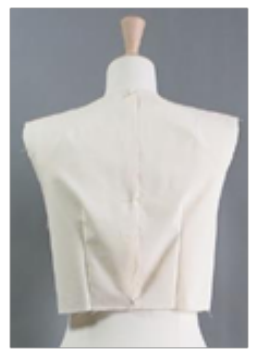

(a) Secoli

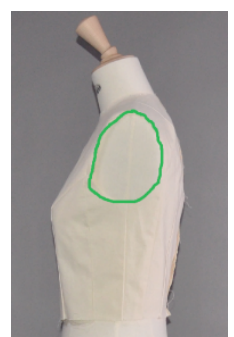

(b) Bunka

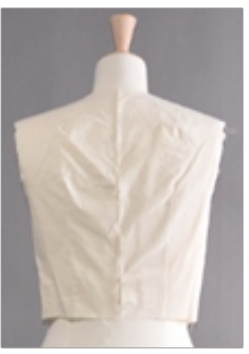

(b) Bunka

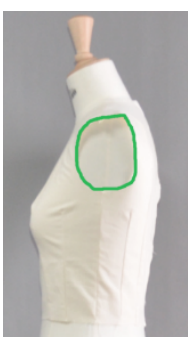

(c) ESMOD

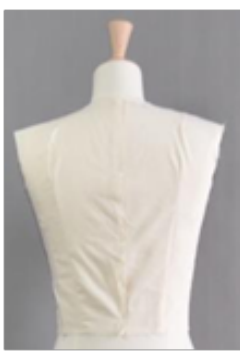

(c) ESMOD

Figure 15. Back view of garments on Stockman dress form

As shown in Table 10, the shoulder angles of the garments differed on the dress forms. However, the subjects stated that there were no differences in shoulder parts. Therefore, it can be seen that differences in the shoulder angle did not affect the appearance of the garment.

\section{CONCLUSIONS}

We investigated the effect of combinations of patternmaking methods and dress forms on the appearance of a basic upper garment. Six basic patterns were made by combining three

Table 11. Significant differences in sensory evaluations

\begin{tabular}{|c|c|c|c|c|c|}
\hline Direction & 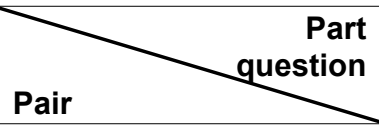 & $\begin{array}{c}\text { All } \\
\text { Question-1 }\end{array}$ & $\begin{array}{c}\text { Shoulder } \\
\text { Question-2 }\end{array}$ & $\begin{array}{c}\text { Bust } \\
\text { Question-2 }\end{array}$ & $\begin{array}{c}\text { Waist } \\
\text { Question-2 }\end{array}$ \\
\hline \multirow{6}{*}{ Front } & $\mathrm{a} 1, \mathrm{~b} 1$ & & & * & \\
\hline & $a 1, c 1$ & $* *$ & & & ** \\
\hline & b1,c1 & * & & ** & $* *$ \\
\hline & a2,b2 & & & & \\
\hline & a2,c2 & & $* *$ & & $* *$ \\
\hline & b2,c2 & & * & ** & ** \\
\hline \multirow{6}{*}{ Side } & a1,b1 & & & & ** \\
\hline & $a 1, c 1$ & ** & & * & ** \\
\hline & b1,c1 & * & & & \\
\hline & a2,b2 & $* *$ & * & & ** \\
\hline & a2,c2 & ** & * & ** & ** \\
\hline & b2,c2 & * & & & \\
\hline \multirow{6}{*}{ Back } & a1,b1 & & & ** & ** \\
\hline & a1,c1 & ** & ** & ** & ** \\
\hline & b1,c1 & $*$ & & * & ** \\
\hline & a2,b2 & & & & \\
\hline & a2,c2 & $* *$ & & ** & $* *$ \\
\hline & b2,c2 & * & & ** & $* *$ \\
\hline
\end{tabular}

*: $0.05 \%$ significant, **: $0.01 \%$ significant 
patternmaking methods from different countries and two dress forms. The basic patterns and the appearance of the garments on the dress forms were compared.

The methods used to calculate the length of the waist darts, bust darts, and shoulder darts and the position of the dart ends differed with the various patternmaking methods used. This resulted in differences in the patterns, and thus had an effect on the appearance of the garments. It is likely that the patternmaking method used in each country optimizes the sizes for their residents' expected body shapes. These differences will affect the appearance of garments. The position of the BP differed among the garments, which resulted in different bust shapes. This is related to the expected garment shape in the market where each patternmaking method is used. It was found that the different patternmaking methods affected the waist shape and silhouette from the side view. The shoulder parts did not affect the sensory evaluation of appearance, even though the shoulder angles differed. However, the shoulder part is related to the comfort of the wearer [12]. Therefore, it is necessary to investigate the relative comfort of garments in the future. Furthermore, investigation on the effect of sleeve on garment appearance will be necessary.

Consequently, the combination of patternmaking method and dress form influenced the garment's appearance. Thus, it is necessary to take this combination into account in relation to the expected body and garment shapes for each market. For global apparel manufacturing, it is necessary to investigate the relationship between patternmaking method and body shape of different countries. Thus, this study will help manufacturer and patternmakers for global marketing.

\section{ACKNOWLEDGMENTS}

This work was supported by the Japan Society for the Promotion of Science (JSPS) KAKENHI Grant number JP24220012.

\section{References}

[1] Kim, K., Otani, T., Takatera, M. (2015). Effect of patternmaker's proficiency on the creation of clothing. Proceedings of the 1st International Symposium on Affective Science and Engineering (ISASE2015), A2-2, March 22-23, 2015, Tokyo, Japan.

[2] Modellistica industriale donna, (2012). Istituto carlo secoli, Italy.

[3] Miyoshi, M. (2013). Fukusō zōkei-gaku riron-hen (Study of dress modeling theory), first edition. Bunka Publishing (Tokyo). [In Japanese]
[4] Become a pattern drafter 1 women's garments, Esmod editions, Paris, France (2009).

[5] Joseph-Armstrong, H. (2010). Patternmaking for fashion design. (Fifth Ed.). Pearson Education, Inc. (New Jersey).

[6] Öberg, I., Ersman, H. (2010). Mönster och konstruktioner för damkläder (Patterns and designs for womenswear), Natur Kultur Allmänlitteratur. [In Swedish]

[7] Kiisel, K. (2013). Draping: the complete course. Laurence King Publishing (London).

[8] Aldrich, W. (2014) Metric pattern cutting for women's wear, fifth edition, Blackwell Publishing (Oxford)

[9] Chen, C-M. (2007). Fit evaluation within the made-tomeasure process. International Journal of Clothing Science and Technology, 19(2), 131-144.

[10] Okabe, K., Yamana, N., Yamamoto, K. (1995). Figure evaluation of the adult females silhouette and relation between the figure and the dress silhouette. Journal of the Japan Research Association for Textile End-uses, 36(3), 295-300.

[11] Nakano, H. (1986). Dress beauty and figure of women. The Japan Research Association for Textile End-Uses, 27(8), 330-335.

[12] Makabe, H., Beppu, M. (1997). The construction of the basic system for the clothing pattern design (part 1). The indispensable measurement items of the upper body. The Japanese Journal of Ergonomics, 33(1), 35-46 [In Japanese].

[13] Kato, S. (1994). Kenwan-bu ni fitto suru kigokochi yoi genkei (Comfortable basic pattern fitted on shoulder and arm part). Research report in Aichi Education University, 53-58 [in Japanese].

[14] Brackelsberg, P., Farrel-Beck, J., Winakor, G. (1986). Comparing fit of basic bodices and skirts altered by traditional and experimental techniques. Clothing and Textiles Research Journal. 5(1), 34-41.

[15] Wang, Z., Newton, E., Ng, R., Zhang, W. (2006). Ease distribution in relation to the $X$-line style jacket. Part 1: Development of a mathematical model. The Journal of the Textile Institute, 97(3), 247-256.

[16] Wang, Z., Newton, E., Ng, R., Zhang, W. (2006). Ease distribution in relation to the $X$-line style jacket. Part 2: Application to pattern alteration, The Journal of the Textile Institute, 97(3), 257-264.

[17] Brockman, Helen L. (1965). The theory of fashion design, John Wiley \& Sons Inc., NY.

[18] Scheffe, H. (1952). An analysis of variance for paired comparisons. Journal of the American Statistical Association, 47, 381-400. 